\title{
New Venues for Science Teacher Education: Self-organizational Pedagogy on the Edge of Chaos
}

\author{
LYUBOV LAROCHE \\ Western Washington University (USA) \\ CYNTHIA NICOL \\ University of British Columbia (Canada) \\ JOLIE MAYER-SMITH \\ University of British Columbia (Canada)
}

\begin{abstract}
This paper describes our attempt to develop a pedagogical practice informed by the concepts of complexity applied to education. The context of our study was the science methods course within an elementary teacher education program. The practice, described here, has overlapped instruction and assignment; teaching and learning; science and the arts; formal and informal education. Prospective teachers, while working in teams of 4-5, taught mini-lessons about science topics to $6^{\text {th }}$ and $7^{\text {th }}$ graders in field settings, and then, collaboratively with the children, produced scientific/artistic digital videos about these topics. As a next step, prospective teachers shared their teaching experiences, classroom observations, and self-produced videos with their university peers. Upon completing this practice, many prospective teachers have changed their ways of thinking about science and science education. We discuss how this practice is informed by and further informs such concepts of complexity as self-organization, chaotic attractors, fluidity, fuzzy boundaries, the edge of chaos, improvisation, adaptation, and transformation.
\end{abstract}


What could be conveyed by it? And how?

What harmony, what cacophony would come out of it?

Do we have any sort of an ear for hearing that kind of thing?

(Serres, 1995, p. 4)

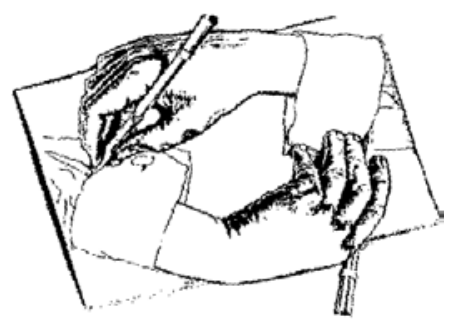

Click on the above image to be linked to an online version of M.C. Escher's "Drawing Hands"

In the famous lithograph by M.C. Escher, entitled "Drawing Hands," two hands draw each other simultaneously. Via an optical illusion, via interplay of light and dark lines, chiaroscuro, the hands emerge gradually out of a two-dimensional imaginary plane into the three-dimensional, seemingly real world. Which hand drew which in the first place? This lithograph can perhaps represent a symbol of metaphorical organization of our world: we create our metaphors and they, in turn, create the realm that we call our reality. As Lakoff and Johnson (1980) write, metaphors are pervasive to our thoughts and actions. Starting from more than three centuries ago, a modern cultural metaphor, a "machine," continually dominates our organizational systems. This includes educational structures that are currently understood, designed, and practiced in terms of mechanics, factory, computer, or market (Doll, 1993; Davis \& Sumara, 1997; Cutright, 2001).

Mechanistic organization requires and values rigid planning, control, clarity, rationality, predicted outcomes, and autonomy of parts of the system; all elements of a machine can be isolated, manipulated, and repaired, if necessary. Organized mechanistically, educational systems, including teacher education programs, function in an abstract isolated space that has little connection with real life outside educational institutions. Within this space, write Davis and Sumara (1997), preparation of pre-service teachers is reduced to lesson planning, test construction, and "how-to" manuals. This arrangement leaves future teachers unprepared for real life school conditions that are often complex, dynamic, and unpredictable. To learn to adapt to ongoing and sometimes unforeseen changes, student teachers must be exposed to the environment beyond university classrooms and made to 
master skills beyond knowing "how-to" manuals. They must be able to improvise, to take risks, and to collaborate with others.

In the light of this understanding, the current trend and challenge is to make teacher preparation programs more field-oriented (Worly \& Fry, 2002). School practica and internships provide field exposures; however, as Davis and Sumara (1997) write, these activities pressure future teachers to fit into the existent curriculum and formal framework of a particular school. When asked to comment on their practicum experiences, preservice teachers often describe them in terms of what is allowed by the sponsor teacher or faculty supervisor. There is little room for improvisation, imagination, and risks within existent school practica arrangements.

This presses us to think that in addition to conventional field experiences, other, more open, fluid, improvisational, and collaborative pedagogical models must be designed to foster development of skills necessary to operate creatively in a complex and dynamic school environment.

These kinds of models cannot be created under the guidance of a mechanistic educational paradigm that values rigid planning, standards, prescribed outcomes, and individual achievement. There is a need for a radically new theoretical framework that would offer different metaphorical lenses to view reality and to organize social systems, including education. This framework is currently evolving from the new science of complexity (Tetenbaum, 1998; Capra, 2002). The science of complexity is an interdisciplinary field, emerging from new developments within a number of scientific disciplines, including ecology, informational technology, chemistry, biology, physics, astronomy, economy, and human consciousness research. This new interdisciplinary science focuses on the evolution of complexity within and between world systems. The process of spontaneous emergence of new complex orders out of seemingly chaotic realms is called self-organization, which is the key concept of the science of complexity. The concepts closely related to self-organization include: interconnectedness within and between apparently random events and networks, openness and sensitivities of systems, and the conditions for the unpredictable to evolve toward the new (Briggs \& Peat, 1999).

Self-organization is the heart of the post-mechanistic approach to epistemology and pedagogy (Doll, 1993). Currently, the self-organizational approach is making its way into secondary, post-secondary, distance, special, global education, as well as to educational organizational structures and leadership. This paper describes our attempt to contribute to the evolving scholarship that theorizes and applies the concept of self-organizational pedagogy to education. Our context is a science education course for students enrolled in a post-baccalaureate teacher education program for which the first author was the course instructor. Our inquiry intended to design a self- 
organizational pedagogical practice and to explore its potential to transform preservice teachers' perspectives on learning and teaching. Educational technology, in particular, digital video production, represented a highlight, or, metaphorically using vocabulary of complexity, the "chaotic attractor" of our project. To describe and analyze our project, let us first introduce the concepts of complexity and self-organization.

\section{Self-Organization as a Process Deeply Embedded in Nature and Culture}

Self-organization is the spontaneous emergence of new and more complex patterns in the system forced into a state far from equilibrium. As Sadar and Abrams (1999) write, "the richness and diversity of interactions between a host of interdependent variables allow complex systems to self-organize. The process of self-organization happens simultaneously, as though by "magic" (p. 83). The classic example of self-organization is Benard cells, the honeycomb-like patterns that emerge throughout a layer of a liquid placed between hot and cold plates. With increasing differences of temperatures between the hot and the cold, the honeycomb-like patterns tend to transform into a new order of complexity, a beautiful spiral.

The result of self-organization in nature can be seen everywhere; it is exhibited through amazing variety of complex forms, patterns, shapes, and interactions around and within us. From atoms, to molecules, to cells, to organisms, to societies, to galaxies, there is no shortage of ever-increasing complexity. Ever-hurrying clouds, mad rivers, intricate snowflakes, busy traffic, street crowds, stock markets, weather patterns, heartbeats, brain functioning, artistic artifacts, scientific discoveries, all of these are results and examples of self-organizational processes. Self-organization seems to be deeply embedded in nature and culture (Prigogine, 1996). As such, this concept offers a more authentic approach to epistemology and to designing social systems than artificial linear mechanistic models (Stadler et al., 1996; Morgan, 1997; Barrow, 1999; Tetenbaum, 1998; Capra, 2002). Self-organization occurs under the following conditions:

- fluid realm,

- turbulences,

- the edge of chaos,

- richness of possibilities,

- complexity of variables,

- presence of a chaotic (or strange) attractor,

- interconnectedness of and intercommunication among all parts of the system. 
A fluid realm allows movement of a substance, juxtaposition of layers, interference of waves, flexibility, and fluctuations. If the conditions are too rigid, too inflexible as in a solid state, the system cannot be transformed into a different state. If there is too much randomness, as in a gaseous state, the system is too disordered for any transformations to occur. The realm of fluidity provides most optimal conditions for transformations via self-organizational processes (Serres, 1995). The flow needs gradients and tensions. In order for self-organization to occur, turbulences and disturbances must push the system out of equilibrium. The state of far-from-equilibrium, also called "the edge of chaos," corresponds to the strange condition of simultaneous co-existence of order and chaos. This state is often referred to as bounded randomness, or constrained freedom. Imagine a little whirlpool created within a running river. It maintains the pattern of its organization despite continuous and chaotic flow of turbulent water through it.

The turbulence can destroy the system or push it into a new order of complexity. In order not to be destroyed by disturbing factors, the system must be creative and adaptable. It has to have richness of choices and possibilities to evolve into a new order of complexity. For instance, under extreme circumstances, the living organism may die or become transformed, depending on its own resources and the possibilities offered by the environment.

There is a power factor, called a "chaotic" or "strange" attractor, which "holds" the system on the edge of chaos, constraining its behavior by a complex pattern within the flowing existence. The vertices and whirlpools manage to maintain their shapes within a turbulent flow. The iron pendulum, when placed between three magnets, is moving seemingly chaotically, but when graphed, its movement reveals a beautiful pattern, which looks somewhat as a butterfly. In these cases, the strange attractor maintains the shape of the vertex or restricts seemingly random movement of a pendulum by a butterfly-like pattern. Applying this to living organisms, strange attractors represent a genetic blueprint that preserves the form of the organisms within the ongoing flow of matter, energy, and information. Extrapolating this to human activities, the attractor could be an idea, a thought, a technique, a memory, a concept, an action, a dream, or anything else that transforms reality, while giving birth to self-organized patterns of a new meaning.

Emergence of self-organizing complex patterns is a nonlinear process with limited predictability. The slightest change can unpredictably bring dramatic results in the system's state. This phenomenon is known as the butterfly effect. It symbolizes the sensitivity of a system within a complex environment. Besides extreme sensitivity to subtle changes, a self-organizing system demonstrates collaborative properties. In order to self-organize simultaneously, all parts of the system must be interconnected; they must be 
able to communicate in a cooperative manner. This reinforces the importance of understanding rules of collective participation and cooperation in selforganizing physical and social systems, including education. Applying the concept of self-organization to pedagogical models, how different would these models be, when compared to traditional practices?

\section{Conceptualization: Self-Organizational Pedagogy}

The scholarship related to application of the concepts of complexity to education is undoubtedly growing (Doll, 1993; Jannone, 1995; Fels and Meyer, 1997; Rea \&Ambrose, 1999; Fels, 1999; Davis \& Sumara, 1996; Mathews, White, and Long, 1999, Davis, Sumara, \& Kepler, 2000; Cutright, 2001, MsCombs-Tolis, 2002; O’Day, 2002; Davis, 2003; Kulburz, 2004; Christensen, 2005, Willinsky, 2005).

Synthesizing this work and reflecting on our own thoughts, traditional mechanistic educational systems are to self-organizational models as machines are to life. As Capra (2002) writes, self-organization is the very characteristic of life. According to Capra, we need to learn from life how to design complex, sustainable, adaptable, living, and evolving organizational systems.

Post-mechanistic, organic pedagogical models correspond to and embrace vital conditions of self-organization, including fluid realm, openness to the information flow, turbulences and changes; freedom within flexible boundaries, richness of possibilities, interconnectedness of all parts of the system, and collective emergence. Fluid learning environments juxtapose formal and informal educational settings by blurring boundaries between schools, universities, nature, and society. Fuzzy and penetrable, fluid environments allow formation and re-formation of new cultural, ontological, and epistemological patterns. Self-organizational pedagogical practices within fluid learning environments are not limited to re-enforcing existent models and are not focused on linearly transmitting information between the uniform "cogs of a machine." To the contrary, self-organizational pedagogy seeks radical novelty, invites risks, nurtures improvisations, and cultivates transformations toward new meanings and new epistemologies.

Imagining self-organizational pedagogy is only part of the challenge. How do we actually practice it? Below, we describe our project that is designed, conducted, and analyzed as a self-organizing educational practice.

\section{Design: Blurring Boundaries and Escaping From "How to" Manuals}

If we intend to create fluid learning environments and practice self-organizational pedagogy, then we must depart from direct instructions, isolated 
classrooms, rigid lesson plans, exclusively formal learning, and individualized approaches to knowledge construction. In relation to science education, we cannot limit instruction to lectures and hands-on lab experiments. We cannot narrow down our assessment strategies to multiple choice tests, lab report sheets, or even essays, for that matter, and we cannot reduce science teacher preparation to "how to" manuals. We must imagine and bring into life practices that embrace risks, playfulness, collaboration, fancy, improvisation, and transformations toward novelty. With this understanding, we designed the project within a science teacher education course that, from our perspective, corresponds to the notion of self-organizational pedagogy, or as we call it, "pedagogy on the edge of chaos."

Our preliminary assessment indicated that majority of prospective teachers participating in the project held traditional views on science as a boring, dry, mechanistically rational discipline and perceived science education as a set of hands-on, student-centered, constructivist laboratory practices, based on the scientific method. Most future teachers did not have previous science background. They were intimidated by learning science and did not look forward to teaching it their classrooms. As a result of the project, we expected some transformations in their thinking about science learning and teaching; however, we did not have clear-cut expectations as to what kind of transformational patterns might emerge. In a true spirit of the theory of complexity, we simply allowed these patterns to emerge out of a noise of superimposed intentions, experiences, and possibilities. Basically, we hoped that prospective teachers would change their attitude toward science and would become more enthusiastic, comfortable, imaginative, and adventurous when teaching it.

The design of the project was intricate and multi-dimensional, with overlapping and entangled layers. The objective was to provide prospective teachers with formal science teaching experiences and informal interactions with children in actual school settings. Our project took place in the large classroom where two teachers collaborated in instructing fifty students, sixth and seventh grades combined.

This project was designed to encompass both instruction and assignment within the science methods course. As a formal segment of the project, preservice teachers had to learn about forms of energy, such as light, sound, magnetic, electrical, gravitational, mechanical, and chemical. Then they had to design a lesson to teach this topic to the school children. The informal dimension of this activity was to produce, in collaboration with elementary students, digital videos related to the above topics. Why videos?

Research related to producing digital videos and other multimedia artifacts within science instruction indicates that such activities create multi-dimensional, cross-disciplinary, self-regulating, and transformational learning 
experiences (Jafai, Y., Marsshall, S. \& Ching, C., 1998; Goldman-Segall, 1998; Jonassen, D, 2000). Such experiences, from our perspective, correspond to the concept of self-organizational pedagogy. Furthermore, we must acknowledge that a contemporary mode of expression is not exclusively written or oral language, but a combination of text, video, and sound. Video is an authentic language of a young generation; we should therefore re-define our current understanding of literacy, expanding it to multimedia use and image-making abilities (Goldman-Segall, 1998).

To implement our vision into practice, we divided our class of nineteen prospective teachers into 4 teaching teams. Each team explored two forms of energy independently. No direct instructions were provided, but guidance from the instructor was available at any time. This way we met one of the requirements of self-organizational pedagogy: guided collective participation. After learning the topic itself, teams brainstormed strategies to be used to teach this topic to elementary students and negotiated possible scripts for videos. This arrangement corresponded to yet another self-organizational condition: bounded randomness. The student teachers we restricted by their particular lesson topic, by the age of students, by the design of the project, and by the limits of time. The rest was up to them; they had a complete freedom of expression within these certain boundaries. Elementary school activity, however, was only the first step of the project.

The next step involved peer teaching in the university classroom. As a course assignment, each team had two class hours to show videos produced with children in order to demonstrate how they had taught their topic to children and to reflect on their teaching. The criteria for the assessment were negotiated collectively. The main requirements were knowledge of the material, interdisciplinary approach, interactivity, and the depth of reflections on formal teaching and informal creative work with elementary students. Self-produced videos were not graded; nevertheless the video production aspect became the brightest highlight of the entire activity. The assessment was based on peer-evaluation, self-evaluation, and instructor's observations. We evaluated the process of growth rather than the product itself.

\section{Collective Emergence: Self-Organizational Pedagogy in Action}

The students were allowed to be as creative, as they wanted. They came up with the themes, the characters, and divided up the work. Essentially, we were just there to help push them in right direction. It was amazing what they were able to come up with. (Reflection written by a prospective teacher)

One of the vital self-organizational conditions is the turbulence that pushes the system toward a creative state, far from equilibrium. And, yes, all participants, pre-service teachers, researchers, and the instructor, definitely 
met this condition. After being introduced to the idea of the project, student teachers agreed to participate. Nevertheless, as they reflected later, there was a strong sense of uncertainty, doubt, and even anxiety. They were not science majors, nor were they video producers. They never learned science independently, nor had they taught it to elementary students. Would it be safer simply to organize their science methods course around direct instruction, lessons plans, and scientific inquiries? Could they afford to experiment when the purpose of their entire teacher program was to learn how to fit into the existent school framework? They needed to be able to deal with the rigidity of the existent rather then with the uncertainty of the possible. The instructor and researchers agonized as well: "Do we have the right to dedicate so much of the class time to our pedagogical explorations?" The instructor was responsible for this course, after all.

Out of a thirty-three hour course span, four hours were dedicated to learning the basics of video production. Another two hours needed for video editing, and six hours had to be designated to working with elementary students. Altogether twelve hours was a large investment of time and effort. What if this would not work? What if our self-organizational pedagogical practice would result in destruction rather than transformation? We were afraid to make a mistake. Capra (2002), applying the concept of self-organization to social reality, emphasizes that self-organizational processes must embrace latitude for errors; without errors and uncertainties there is no progress. Unfortunately, we are currently trapped within a mechanistically structured educational system, which does not allow any errors and all improvisations are "no-no."

Despite all doubts, we decided to take a risk, since risk-taking is one of the characteristics of self-organizational pedagogy that we conceptualized. We must practice what we preach. The student teachers' willingness to share our risk, despite their anxieties, could perhaps be attributed to good timing. We started this project after the instructor had already established trust and had developed the rapport with the students. "We must begin where we are," writes Bill Doll (1993) and with this wisdom in mind, we began our journey.

After initial disturbances in the form of anxiety and even fear, there was an increasing sense of excitement and inspiration. The four-hour workshop enabled prospective teachers to grasp the basics of videotaping and editing, using imovie program. Student teachers were surprised to find that the whole process of learning to produce digital videos was much easier then they initially thought. Those who were more advanced, helped others. The same happened with researching and learning about forms of energy. Collaborative learning went beyond team boundaries; members of different teams interacted, helping each other to understand the material. 
If some of them knew interesting activities related to the topic of others, they readily shared the information. The common and unusual goal of the project had "glued" the group into one evolving organism. The role of the course instructor has definitely changed. She became a guiding and participating member rather than a dictating and transmitting factor.

When time came to visit a school, preservice teachers were equipped with knowledge of their topic, interactive strategies and materials for instructing children, and tentative scripts for video production. Each team of four or five prospective teachers worked with approximately ten children. The classroom was large enough to provide each group of teachers and children an "individual corner" so they would not disturb each other too much. More so, the park and playground behind the school provided an abundance of space and possibilities for the creative work. The real challenge was the time limit. In just two visits, three hours each, prospective teachers had to interactively introduce relevant topics to school students and collectively produce videos.

During the first actual meeting with school students, each teaching team introduced their two forms of energy to the children. The teaching element of the project went relatively smoothly: children enthusiastically participated in experiments and problem-solving activities. Each teaching team designed their own strategies to assess children's learning and they were satisfied with the outcome. The video component, however, brought some tensions and frustrations. Although prospective teachers had initial, pre-made ideas for movie scripts, they understood quickly that prescribed scenarios would not work. Children had their own ideas and student teachers were prepared to listen to children's voices. The problem was that the chorus of children's voices was rather chaotic. It seemed impossible to reach any consensus, to create any pattern out of the cacophony of various ideas. After their first visit, prospective teachers left the elementary classroom with the sense of the failure in relation to the movie making portion. They were not quite so enthusiastic about their second school visit. Surprise!

In the time between our two visits, a week apart, school students conducted additional, independent research related to their topics and discussed movie ideas among themselves. They reached tentative consensus regarding their movie scripts. Patterns have begun emerging out of random mixture of ideas. Obviously intrinsically motivated, children prepared songs, games, stories, and science demonstrations. They brought costumes and other accessories. The movie-making aspect of the project became a powerful "chaotic" attractor to them. They couldn't wait to start the actual video production. Using the seeds of children's imaginative ideas, prospective teachers managed to guide the process of collective improvisation. Sawyer (2003), who connected the theory of improvisation with the complexity theory, writes 
that dialogic improvisation is a self-organizing process. Through trial and errors, student teachers learned not to impose, but to guide the process of collective emergence; they learned how to adapt to the unplanned.

Self-produced videos integrated science, the arts, classroom experiments, and outdoor activities. All four of them were structured around contexts that were appealing and understandable to middle school children. As an example, one of the groups created an X-Files type video, entitled "Plant Files." ${ }^{1}$ This video illustrated the interaction of light and chemical energy during the process of photosynthesis. This scientific concept was embedded into the mystery. The "Plant Files" takes place in a plant museum, where one of the rarest plants was dying. Detectives were brought in to investigate the crime scene that leads them to two juvenile delinquents who have been sneaking into the museum and depriving the rare plant of light. It was fascinating to observe the joy of overlapped play and learning both at the elementary and prospective teachers' level.

After completing the school project, teaching teams taught their topic to classmates, as they taught it to the school children. Their also demonstrated their videos and shared their experiences of actual school teaching and video producing. Besides open class discussions, we also conducted videotaped individual interviews with project participants. The instructor's observations and anonymous course evaluations also contributed to the bulk of our data.

\section{Transformative Patterns in Prospective Teachers' Thinking about Learning and Teaching Science}

We believe that in designing and conducting this project, we met main requirements of self-organization, including bounded randomness, guided collective participation, and complexity of the design. By blurring various boundaries, we assured fluidity of our learning environment. We facilitated school-university interactions and integrated:

- formal and informal activities,

- teaching and learning,

- instruction and assessment

- science, arts, and educational technology.

We nurtured possibilities for free flow of information and interactions. We pursued desirable goals rather than rigidly planned outcomes. As Swenk (2001) writes, if we accept self-organization as a dominant concept, then we should acknowledge that rigid planning is not only unrealistic, but dangerous. Self-organizational planning allows fuzziness, ambiguity, and open options. 
Our data indicated that transformational patterns emerged in student teachers' thinking about science and science education. All but one, who selected to drop out of the project, indicated that they no longer perceive science as a dry and methodological discipline. They learned to see science everywhere, to integrate scientific experiments with artistic activities, to guide rather than to impose, to take risks, and to improvise collectively. They learned not to underestimate elementary students' abilities and creativities. They were fascinated by the childrens' imaginative worlds.

Prospective teachers further commented that this project was one of the most enjoyable and beneficial learning experiences throughout the entire teacher education program. They expressed their amazement as to how much content they learned while "playing" and how many activities were added to their collection of teaching strategies. Prospective teachers appreciated the spirit of collaboration that "glued" their class closer together. The informal learning environment helped them to see qualities of their classmates that are not normally revealed in formal and rigid university classes. This project also strengthened the rapport between the class and the instructor. Prospective teachers especially valued the moviemaking part of the project, which became an attractor, a motivational factor for the self-organizational practice described here.

Prospective teachers indicated that making videos was engaging and highly motivating process that prompted them to rethink science education in innovative ways, beyond textbook-driven curriculum and lab experiences. They expressed excitement at seeing their own videos produced with children as well as those of their classmates. It was rewarding for them to gain new perspectives on themselves and their capacities regarding learning and teaching science and producing digital artifacts. Making movies helped them to overcome their apprehensions and to master new technical and intellectual skills they had previously considered beyond their abilities. When asked how the project would be different if instead of movies they created something else, for instance, "scientific" plays with children, the student teachers commented that making movies produces a tangible product that could be preserved and shared down the road. They felt empowered by being able to use a cuttingedge approach to teaching science. Many of them intended to conduct similar projects in their own teaching. Some of them commented that making movies influenced their cognitive process. They started to view the world differently: now they saw an image-enriched world around them. Several students extended their newly gained skills into other projects, selecting to make videos as alternative format to writing academic papers for their final class assignment. 


\section{Implications and Fluid Conclusion: The Story Always Begins...}

Future teachers strongly recommended incorporating the projects of this nature into the teacher education program on a routine basis and wider scale, and we strongly agree with their opinion. We believe our study could be viewed as one of many "seeds" of growth toward understanding and implementing post-mechanistic, self-organizational pedagogy. We encourage teacher educators to probe into the projects of these nature, no matter how challenging and risky they are. This risk will pay off. From an anonymous course evaluation:

The video production exercise was one of my best experiences to date in the education program. It takes courage to try new and perhaps radical things. Only by changing our perspectives can we become better teachers. Thank you for taking the risk, for most of us it really paid off."

This paragraph signifies new growth, new complexity, and a new story within the established mechanistic system. This is the essence of a fluid, self-organizational conclusion: the story always begins.

\section{Note}

1. This video can be downloaded from $\underline{\mathrm{http}} / \mathrm{/} /$ media.wce.wwu.edu/larochl/ plantfiles.wmv

\section{References}

Barrow, J.D. 1999. Between Inner and Outer Space. Oxford: Oxford University Press. Bohm, D. and D.F. Peat. 2000. Science, Order, and Creativity. London: Routledge.

Capra, F. 2002. The Hidden Connections: Integrating the Biological, Cognitive, and Social Dimensions of Life into a Science of Sustainability. New York: Doubleday.

Christensen, S.A. and C. William. 2005. Can schools improve? Phi Delta Kappan 86 (7): 545-546

Coveney, P. and R. Highfield. 1995. Frontiers of Complexity: The Search for Order in a Chaotic World. New York: Random House.

Cutright, M. 2001. Chaos Theory and Higher Education: Leadership, Planning and Policy. New York: Peter Lang.

Davis, B. and D. Sumara. 1997. Cognition, complexity, and teacher education. Harvard Educational Review 67 (1): 105-125.

Davis, B., D. Sumara, and R. Luce-Kapler. 2000. Engaging Minds: Learning and Teaching in a Complex World. Mahwah, NJ: L. Erlbaum Associates.

Davis, B. 2003. Understanding learning systems: Mathematics education and complexity science. Journal for Research in Mathematics Education 34 (2): 137-167.

Dever, J.T. 1997. Reconciling Educational Leadership and the Learning Organization. Community College Review 25 (2): 57-63. 
Doll, W. E. 1993. A Post-Modern Perspective on Curriculum. New York: Teachers College Press.

Goldman-Segall, R. (1998). Points of Viewing Children's Thinking: A Digital Ethnographer's Journey. Mathwah, NJ: Lawrence Erlbaum Associates.

Jannone, R. 1995. Chaos theory and its application for curriculum and teaching. Education 115 (4): 541-547.

Jafai, Y., S. Marshall, and C. Ching. 1998. Collaborative educational multimedia design by children: Do all learners benefit equally? Paper presented at the National Educating Computing Conference, San Diego, CA, June 22-24.

Jonassen, D.H. 2000. Transforming learning with technology: beyond modernism and post-modernism or whoever controls the technology creates the reality. Educational Technology 20 (2): 21-25.

Kauffman, S. 1995. At Home in the Universe. The Search for the Laws of Self-Organization and Complexity. Oxford, UK: Oxford University Press.

Kylburz, L. 2004. Meaning Finds a Way: Chaos (Theory) and Composition. College English 66 (5): 503-523.

Lakoff, G. and Johnson, M. 1980. Metaphors we Live By. Chicago: University of Chicago Press.

Mathews, K.M., White, M.C., and Long, R.G. 1999. Why study the complexity sciences in social sciences. Human Relations 52 (14): 439-440.

McCombs-Tolis, J. 2002. Serving students with disabilities via individualized educational plan (IEP) meeting: employing a self-Organizing system perspective as a philosophical agent for change. Educational Horizons 81 (1): 33-37.

Morgan, G. 1997. Images of Organization. $2^{\text {nd }}$ edition. Thousand Oaks, CA: Sage Publications

O'Day, J. A. 2002. Complexity, accountability, and school improvement. Harvard Educational Review 72 (3): 293-329.

Rea, D. and K. Ambrose. 1999. A "conceptual continuum" for facilitating complex education: Teaching and learning on the edge of chaos. Paper presented at the Annual Meeting of the American Educational Research Association. Montreal, Canada, April 20-22.

Sardar, Z. and I. Abrams. 1999. Introducing Chaos. Cambridge: Icon Books, Ltd.

Sawyer, K. 2003. Improvised Dialogues. Emergence and Creativity in Conversation. London: Alex Publishing.

Stagler, M., V. Gunter, K. Veter, J. Haynes, and P. Kruse. 1996. Nonlinear phenomena in learning process. In Learning as Self-Organization, edited by K. Pribram and J. King, Mahwah, NJ: Lawrence Erlbaum Associates.

Serres, M. 1995. Genesis. Ann Arbor, MI: University of Michigan Press.

Swenk, J. 2001. A chaos theory metaphor for strategic planning. In: Chaos Theory $\mathcal{E}$ Higher Education: Leadership, Planning, \& Policy, edited by M. Cutright, New York: Peter Lang.

Tetenbaum, T.J. 1998. Shifting paradigms: from Newton to chaos. Organizational Dynamics 26 (4): 21-31.

Warren, K., C. Franklin, and C.L. Streeter. 1998. New directions in systems theory: chaos and complexity. Social Work 43 (4): 357-373.

Wheatley, M.J. 1992. Leadership and the New Science: Learning About Organization From 
an Orderly Universe. San Francisco: Berrett-Koehler Publishers.

Willinsky, J. (2005). Just say know? Schooling in the knowledge society. Educational Theory, 55 (1): 97-111.

Whitehead, A. N. 1929/1967. The Aims of Dducation. New York: Free Press.

Willinsky, J. 2005. Just say know? Schooling in the knowledge society. Educational Theory 55 (1): 97-111.

Worly, V. and P. Fry 2002. Toward philosophy of making teachers: teacher training, education, preparation. Action in Teacher Education 14 (3): vii-xi.

\section{About the Authors}

Lyubov Laroche is an Assistant Director and Faculty in the Everett Education Center, Woodring School of Education at the Western Washington University. Her teaching and research interests include teacher education, science education, imaginative approach to teaching and learning, chaos and complexity applied to education, and educational technology. She can be reached at Lyubov.Laroche@wwu.edu

Cynthia Nicol is an Associate Professor in mathematics education in the Department of Curriculum Studies at the University of British Columbia. Her current research projects include community-based action research, Indigenous education, culturally responsive pedagogy, and the use of technology for learning to teach mathematics in multiple contexts. She can be reached atcynthia.nicol@ubc.ca

Jolie Mayer-Smith is an Associate Professor and Deputy Head in the Department of Curriculum Studies at University of British Columbia. Her teaching and research interests include teacher education, post-secondary science teaching and learning, genetics education, and intergenerational environmental education. She can be reached at jolie. mayer-smith@ubc.ca.

(C) Copyright 2007. The authors, Lyubov Laroche, Cynthia Nicol, and Jolie Mayer-Smith, assign to the University of Alberta and other educational and non-profit institutions a non-exclusive license to use this document for personal use and in courses of instruction provided that the article is used in full and this copyright statement is reproduced. The authors also grant a nonexclusive license to the University of Alberta to publish this document in full on the World Wide Web, and for the document to be published on mirrors on the World Wide Web. Any other usage is prohibited without the express permission of authors. 
